\title{
Respiratory motion tracking system of hepatocellular carcinoma treatment using FUS
}

Hiroyuki Fukuda1*, Nobutaka Doba ${ }^{1}$, Kazushi Numata', Ayako Takeda ${ }^{1}$, Yoshiharu Hao ${ }^{1}$, Akito Nozaki ${ }^{1}$, Masaaki Kondo', Makoto Chuma', Shin Maeda', Tatsuya Fujii' ${ }^{2}$, Dongjuin Lee ${ }^{2}$, Norihiro Koizumi ${ }^{2}$, Hiroyuki Tsukihara², Mamoru Mitsuishi ${ }^{2}$, Yoichiro Matsumoto ${ }^{2}$, Kiyoshi Yoshinaka ${ }^{3}$, Katsuaki Tanaka'

From Current and Future Applications of Focused Ultrasound 2014. 4th International Symposium Washington, D.C, USA. 12-16 October 2014

\section{Background/introduction}

One of the reasons for the long treatment time of FUS for HCC compared with RFA is that we have to adjust the target lesion which has a respiratory movement. In this study, we evaluated the usefulness of respiratory tracking system for the FUS monitoring images of hepatocellular carcinoma (HCC).

\section{Methods}

The respiratory motion trackings for the focal lesions were performed in 6 patients with HCC. The maximum diameter of the tumors measured on sonography ranged from 10 to $50 \mathrm{~mm}$ (mean, $25 \mathrm{~mm}$; SD, $5.5 \mathrm{~mm}$ ). The FUS system (Mianyong Haifu Tech) was used under ultrasound guidance. By using the video images during

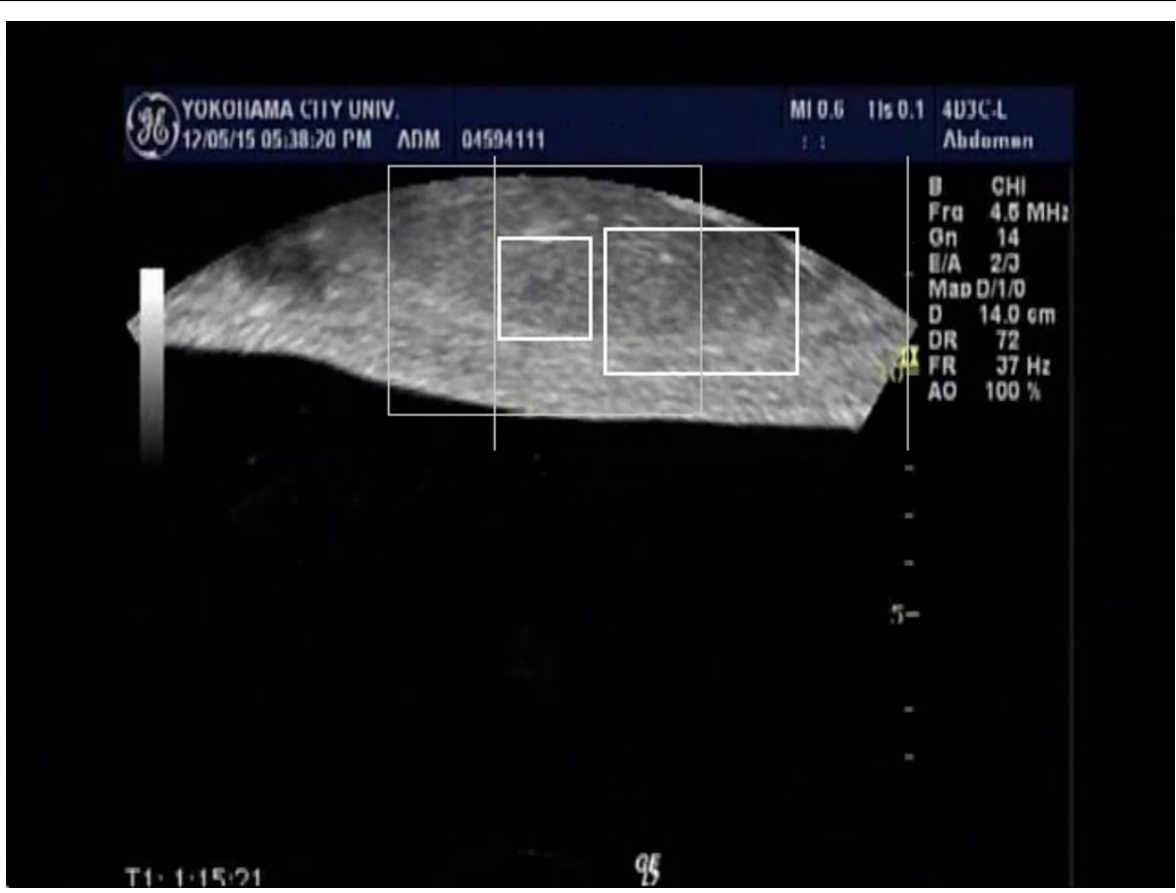

Figure 1 Tumor of the monitor ultrasonography was tracked in the small square, and it was tracked successfully in breath out position

YYokohama City University, Yokohama, Japan

Full list of author information is available at the end of the article

C 2015 Fukuda et al; licensee BioMed Central Ltd. This is an Open Access article distributed under the terms of the Creative Commons 

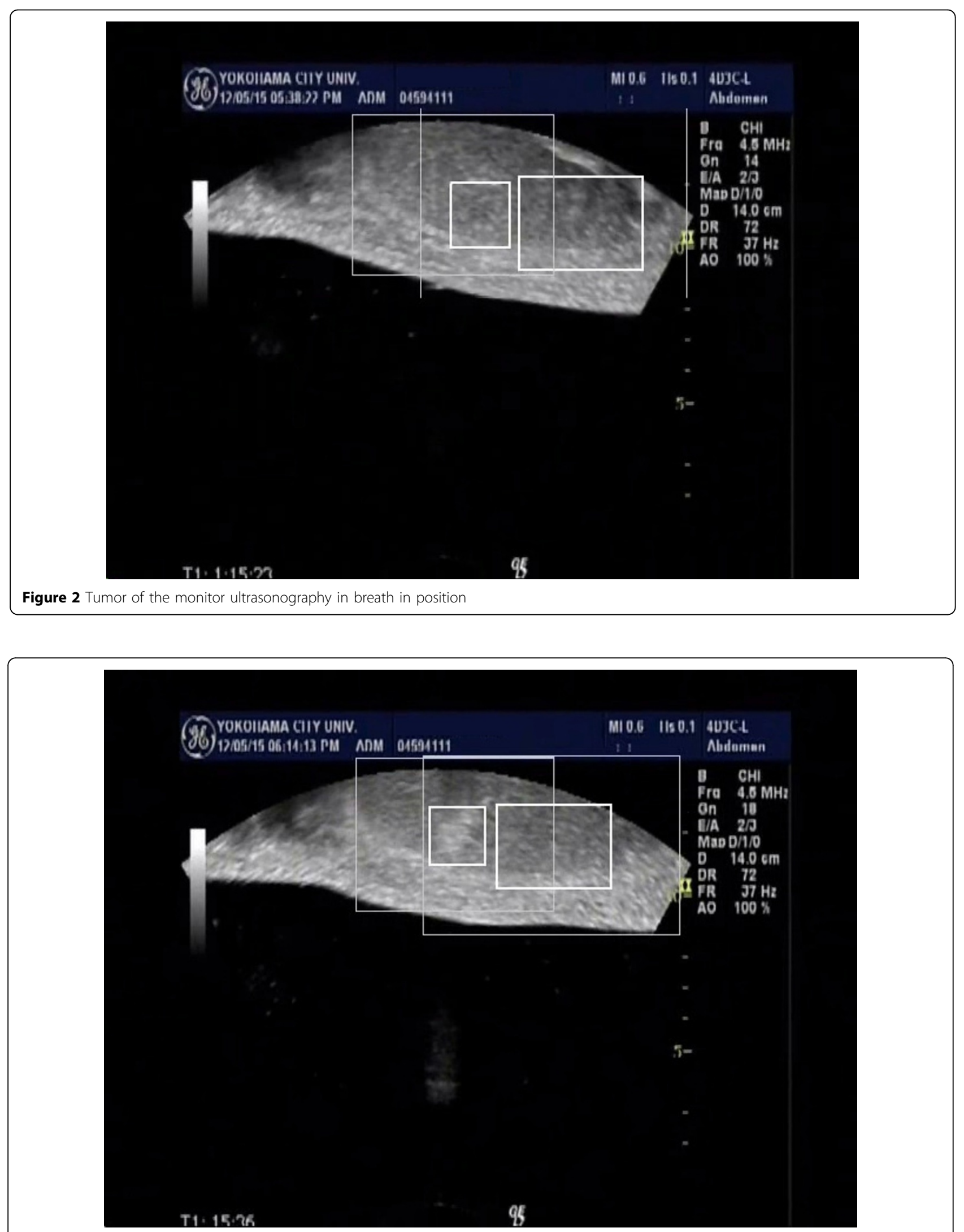

Figure 3 Tumor surrounded with hyperecho after the FUS treatment was also tracked successfully in both breath out position 


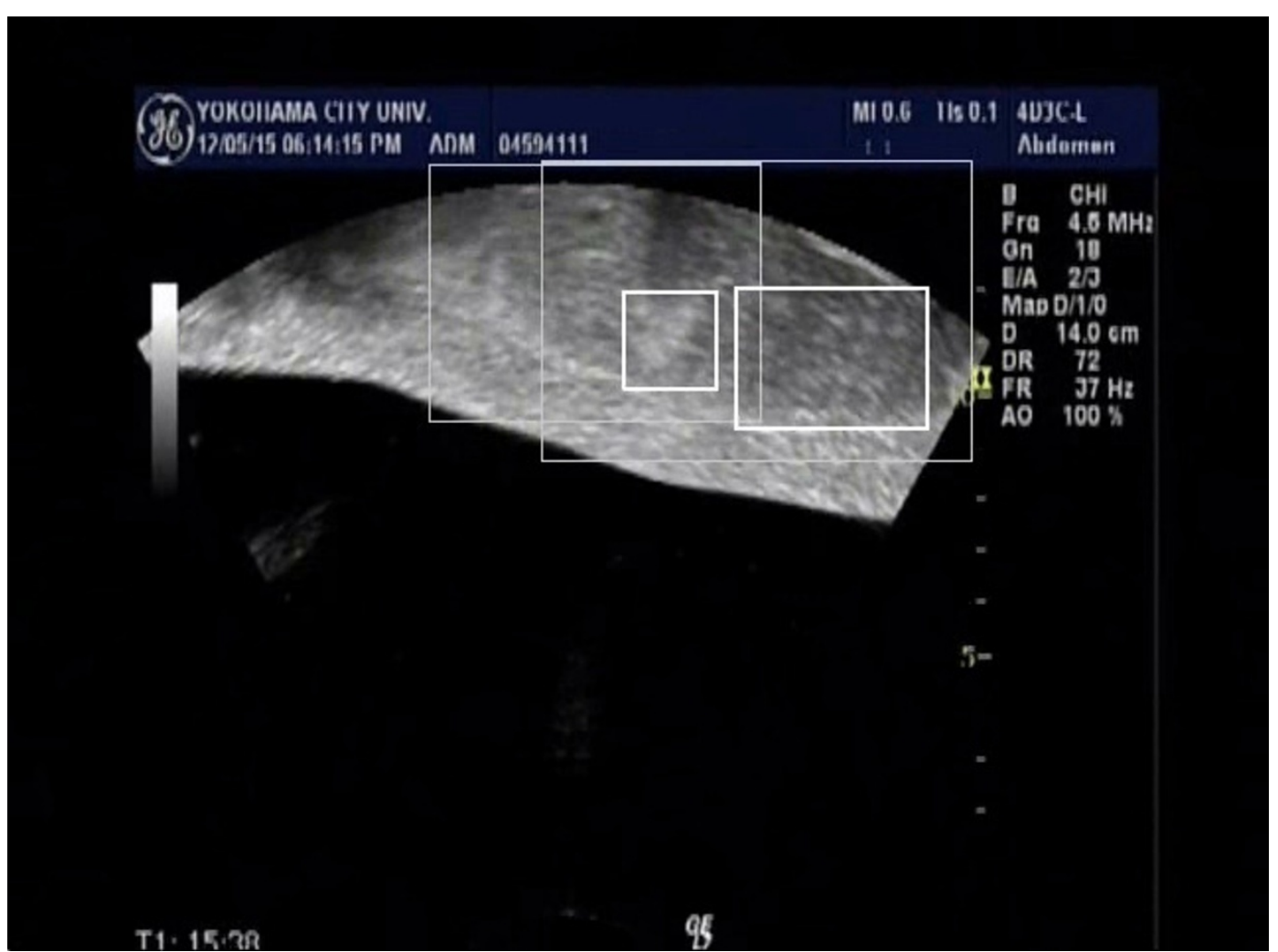

Figure 4 Tumor surrounded with hyperecho after the FUS treatment in both breath in position

the FUS treatment, we evaluated the respiratory motion tracking system retrospectively. Template matching method was applied to this respiratory motion tracking software.

\section{Results and conclusions}

In 6 cases of $\mathrm{HCC}$, we evaluated the tracking system according to the tumor size, and the tracking of the tumor larger $3 \mathrm{~cm}$ in diameter were successfully performed in all cases $(n=2)$. On the other hand, the tracking of the tumor smaller than $3 \mathrm{~cm}$ were performed successfully in 3 out of 4 cases. The reason for motion trackings were not performed well was thought to be that the tumor contour became unclear because the maximal cross section of the tumor go out of the plane by the respiratory movement. By using the video images during the FUS treatment (Fig. 1, Fig. 2), we evaluated the respiratory tracking, and the tumor was successfully tracked. And the tumor after FUS treatment was also tracked well even after the presence of the hyperecho around the tumor (Fig. 3, Fig. 4). In conclusion, the respiratory motion tracking using template matching method was successfully performed and have a possibility to shorten the FUS treatment time.

\section{Authors' details}

${ }^{1}$ Yokohama City University, Yokohama, Japan. ${ }^{2}$ The University of Tokyo, Tokyo, Japan. ${ }^{3}$ National Institute of Advanced Industrial Science and Technology, Tsukuba, Japan.

Published: 30 June 2015

doi:10.1186/2050-5736-3-S1-P47

Cite this article as: Fukuda et al:: Respiratory motion tracking system of hepatocellular carcinoma treatment using FUS. Journal of Therapeutic Ultrasound 2015 3(Suppl 1):P47.

\section{Submit your next manuscript to BioMed Central and take full advantage of:}

- Convenient online submission

- Thorough peer review

- No space constraints or color figure charges

- Immediate publication on acceptance

- Inclusion in PubMed, CAS, Scopus and Google Scholar

- Research which is freely available for redistribution 